\title{
Article \\ Activation of the ABA Signal Pathway Mediated by GABA Improves the Drought Resistance of Apple Seedlings
}

\author{
Chenlu Liu, Hongtao Wang, Xiuzhi Zhang, Fengwang Ma, Tianli Guo and Cuiying Li *
}

Citation: Liu, C.; Wang, H.; Zhang, X.; Ma, F.; Guo, T.; Li, C. Activation of the ABA Signal Pathway Mediated by GABA Improves the Drought Resistance of Apple Seedlings. Int. J. Mol. Sci. 2021, 22, 12676. https:// doi.org/10.3390/ijms222312676

Academic Editors: Farzana Sabir and Luísa Carvalho

Received: 1 November 2021

Accepted: 22 November 2021

Published: 24 November 2021

Publisher's Note: MDPI stays neutral with regard to jurisdictional claims in published maps and institutional affiliations.

Copyright: (c) 2021 by the authors. Licensee MDPI, Basel, Switzerland. This article is an open access article distributed under the terms and conditions of the Creative Commons Attribution (CC BY) license (https:// creativecommons.org/licenses/by/ $4.0 /)$.
State Key Laboratory of Crop Stress Biology for Arid Areas/Shaanxi Key Laboratory of Apple, College of Horticulture, Northwest A\&F University, Xianyang 712100, China; 20180502741cl@nwafu.edu.cn (C.L.); wht17854273332@163.com (H.W.); zhangxiuzhi0124@163.com (X.Z.); fwm64@nwafu.edu.cn (F.M.); guo1003tianli@nwafu.edu.cn (T.G.)

* Correspondence: lcy1262@nwafu.edu.cn

Abstract: Drought seriously affects the yield and quality of apples. $\gamma$-aminobutyric acid (GABA) plays an important role in the responses of plants to various stresses. However, the role and possible mechanism of GABA in the drought response of apple seedlings remain unknown. To explore the effect of GABA on apple seedlings under drought stress, seedlings of Malus hupehensis were treated with seven concentrations of GABA, and the response of seedlings under 15-day drought stress was observed. The results showed that $0.5 \mathrm{mM}$ GABA was the most effective at relieving drought stress. Treatment with GABA reduced the relative electrical conductivity and MDA content of leaves induced by drought stress and significantly increased the relative water content of leaves. Exogenous GABA significantly decreased the stomatal conductance and intercellular carbon dioxide concentration and transpiration rate, and it significantly increased the photosynthetic rate under drought. GABA also reduced the accumulation of superoxide anions and hydrogen peroxide in leaf tissues under drought and increased the activities of POD, SOD, and CAT and the content of GABA. Exogenous treatment with GABA acted through the accumulation of abscisic acid (ABA) in the leaves to significantly decrease stomatal conductance and increase the stomatal closure rate, and the levels of expression of ABA-related genes PYL4, ABI1, ABI2, HAB1, ABF3, and OST1 changed in response to drought. Taken together, exogenous GABA can enhance the drought tolerance of apple seedlings.

Keywords: exogenous; GABA; antioxidant enzymes; stomata; ABA; drought stress

\section{Introduction}

Actively growing plants are usually faced with various unsuitable conditions, such as drought, salt, alkaline, and nutritional stresses [1-3]. Among these conditions, drought stress has the most serious effect on plant growth [4]. It has been demonstrated that terrestrial plants in approximately $40 \%$ of the world's arable land suffer from a water deficit [5]. In drought-affected areas, inadequate water use for agriculture is lead to a significant decline in crop yield and quality. Apples are one of the most important fruit crops in the world. However, the main limiting factor of apple production is water deficit. Increasing durations of drought have been reported to induce a series of physiological and biochemical changes, including a reduction in the germination rate and number of seedlings [6], stomatal closure [7], a reduction in the amino acid content and activity of antioxidant enzymes [8], and decreased leaf relative water content (RWC) and cell membrane stability (CMS). Plants adapt to arid environments by adjusting their stomatal conductance to change the transpiration rate and water use efficiency. Moreover, the relationship between stomatal function and plant water status is very complex and involves many factors [9-11].

The plant hormone abscisic acid (ABA) plays an important role in plant growth. ABA has been proven to be the main chemical signal substance that regulates stomatal opening and development [12]. The ABA signaling pathway contains four core components: the 
ABA receptor PYR/PYL/RCAR [13], protein phosphatase PP2C [14], SNF1-associated kinase 2 [15], and transcription factor ABF/AREB [16]. In the absence of ABA, PP2C inactivates SnRK2 by direct dephosphorylation, so that it cannot activate the downstream transcription factor ABF/AREB. Thus, the ABA signaling pathway cannot be activated. When plants produce a large amount of ABA under drought stress, PYR/PYL/RCAR binds with ABA to form a complex and interacts with the PP2Cs to inhibit their activity. This interaction depends on serine-threonine kinase OPEN STOMATA 1 (OST1) [17], which activates Snrk2 and then dephosphorylates the downstream transcription factor AREB/ABF to activate the ABA signaling pathway [18,19]. OST1 encodes SNF1-associated protein kinase 2 (SnRK2), which participates in ABA-mediated stomatal closure [20].

$\gamma$-aminobutyric acid (GABA), a non-protein amino acid, was first discovered in potato tubers half a century ago [21] as a signal substance or metabolite [22,23]. GABA is a four-carbon, non-protein amino acid that exists in virtually all known prokaryotes and eukaryotes. GABA is considered a significant metabolite and signal, and its biosynthesis and roles in plants have been proved [23]. GABA is synthesized in the cytosol by glutamate decarboxylase (GAD) in plants. Extensive research in the past demonstrated that abiotic stresses, such as high temperatures [24,25], salinity [26,27], osmotic stress [28], and iron deficiency [1], can lead to the accumulation of GABA in plant cells. Recent studies provided evidence of the beneficial effects of $\gamma$-aminobutyric acid (GABA) on abiotic stress in plants: Exogenously applied GABA can effectively enhance the adaptation of different plant species to drought, high temperature, salt stress, and alkaline stress $[29,30]$. The application of GABA particularly regulated glutathione metabolism, carbon fixation, and amino acid metabolism related to better thermotolerance [31]. GABA caused further enhancements in antioxidant enzyme activity and superoxide dismutase activities when plants were subjected to Cd [32]. GABA pretreatment alleviated iron deficiency-induced chlorosis and growth inhibition and effectively increased iron content roots [1]. As an exogenous substance, GABA has been proven to improve the tolerance of many plants under stress, but whether GABA can improve the drought tolerance of apple seedlings and how it is regulated have not been clearly elucidated.

Although it is well-known that GABA is implicated in plant tolerance and it plays a role as a signaling molecule, its effect on phytohormones is not clear. Previous results indicated that GABA works in harmony with phytohormones and suggested that regulation of phytohormones by exogenous GABA could be important in reducing plant stress [33], and exogenous GABA may be involved in ABA signaling pathways under salt stress [34]. However, there is little information about effects of GABA on plant hormones in apple seedlings under drought stress.

The objectives of this study were (1) to investigate whether GABA could enhance drought tolerance in apple (Malus hupehensis) through the modulation of physiological and biochemical pathways and (2) to determine the mechanism of exogenous GABA in the improvement of drought tolerance.

\section{Results}

\subsection{Screening for the Optimal Concentration of $G A B A$}

Treatment with $0.5 \mathrm{mM}$ GABA effectively improved the drought tolerance of apple seedlings (Figure 1A). Drought stress significantly decreased the RWC of leaves compared with the control. The RWC values in leaves were found to be $92 \%, 70 \%, 74 \%, 80 \%, 78 \%$, $81 \%, 76 \%$, and $76 \%$ in groups I, II, III, IV, V, VI, VII, and VIII, respectively (Figure 1B).

The values of REL in the III and IV groups were the smallest (Figure 1C). We determined that $0.5 \mathrm{mM}$ is the most suitable concentration to use to alleviate drought. GABA increased the RWC and reduced the REL. 

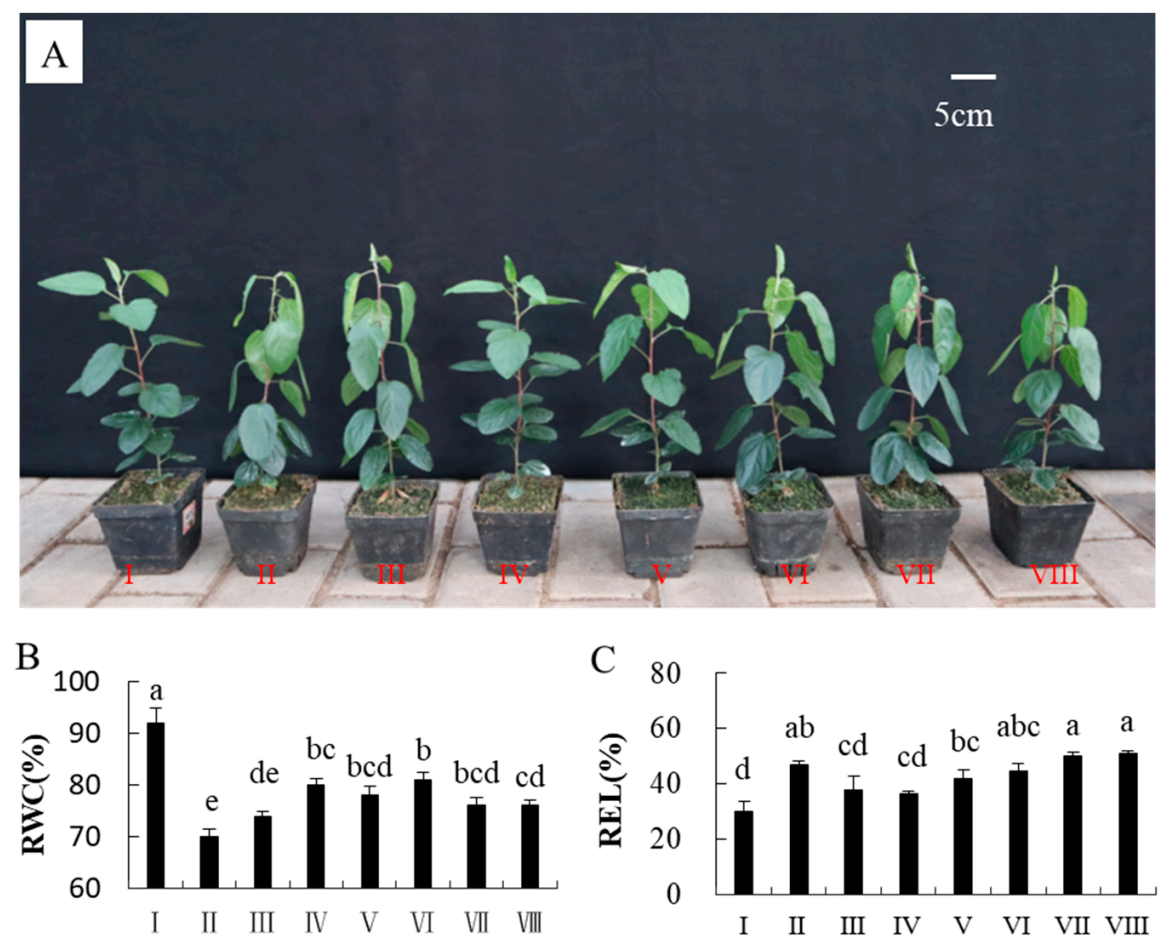

Figure 1. Growth status of seedlings treated with different concentrations of GABA (CK, 0, 0.25 , $0.5,1,2,5$, and $8 \mathrm{mM}$ ) under drought stress (A). Graphical representation for the data of relative water content (RWC) (B) and relative electrolyte leakage (REL) (C) of seedlings treated with varying concentrations of GABA under drought stress. Data are the mean \pm SD $(n=3)$. Tukey's multiple range test (two-way) based on an analysis of variance (ANOVA) was utilized to analyze the data. Values with different letters are significantly different $(p<0.05)$.

\subsection{Plant Growth}

Drought stress had strong negative effects on plant growth. The leaves in the D treatments were severely wilted. However, the leaves treated with GABA still maintained good growth under drought stress (Figure 2A).

Under drought treatment, REL increased by $83.2 \%$, and RWC decreased by $20.9 \%$ in group D compared with the control (Figure 2B,C). However, exogenous GABA significantly alleviated those decreases when compared with drought-stressed plants that had received no such supplementation. The values increased by $53.6 \%$ for REL (Figure $2 \mathrm{~B}$ ), while the degree of decreases was only $14.9 \%$ for RWC (Figure 2C) when compared with the control values; moreover, the content of MDA in D + G was 30.7\% less than that in D (Figure 2D).

\subsection{Gas Exchange Parameters}

The values of the instantaneous gas exchange parameters measured in this study to investigate the changes in the photosynthetic capability of apple seedlings subjected to drought stress are shown in Figure 3. The highest value $\left(7.3 \mu \mathrm{mol} \mathrm{m}{ }^{-2} \mathrm{~s}^{-1}\right)$ of $\mathrm{Pn}$ was found in the $\mathrm{CK}+\mathrm{G}$ treatment; the value in the $\mathrm{CK}$ was $7.1 \mu \mathrm{mol} \mathrm{m}{ }^{-2} \mathrm{~s}^{-1}$, and there was no significant difference between the $C K$ and $C K+G$ (Figure 3A). Compared with that in the $\mathrm{CK}$, the Pn values measured under drought conditions decreased significantly by $65.3 \%$ and $38.5 \%$ in the D and D + G treatments, respectively. The Tr showed no remarkable differences among the $\mathrm{CK}$ and $\mathrm{CK}+\mathrm{G}$ treatments, and drought stress caused a significant reduction in $\operatorname{Tr}$ (Figure $3 \mathrm{~B}$ ). Although the $\mathrm{D}$ and $\mathrm{D}+\mathrm{G}$ treatments caused $\mathrm{Ci}$ to decrease compared with that of the $\mathrm{CK}$ treatment, the $\mathrm{Ci}$ of $\mathrm{D}$ treatment was $55.4 \%$ higher than that of D + G (Figure 3C). Simultaneously, the value of Gs obviously decreased under drought stress. Compared with that of the CK, the Gs of D treatment was reduced by $72.3 \%$, and the Gs of D + G was reduced by $89.3 \%$ (Figure 3D). There was no significant difference between the CK and CK + G. 

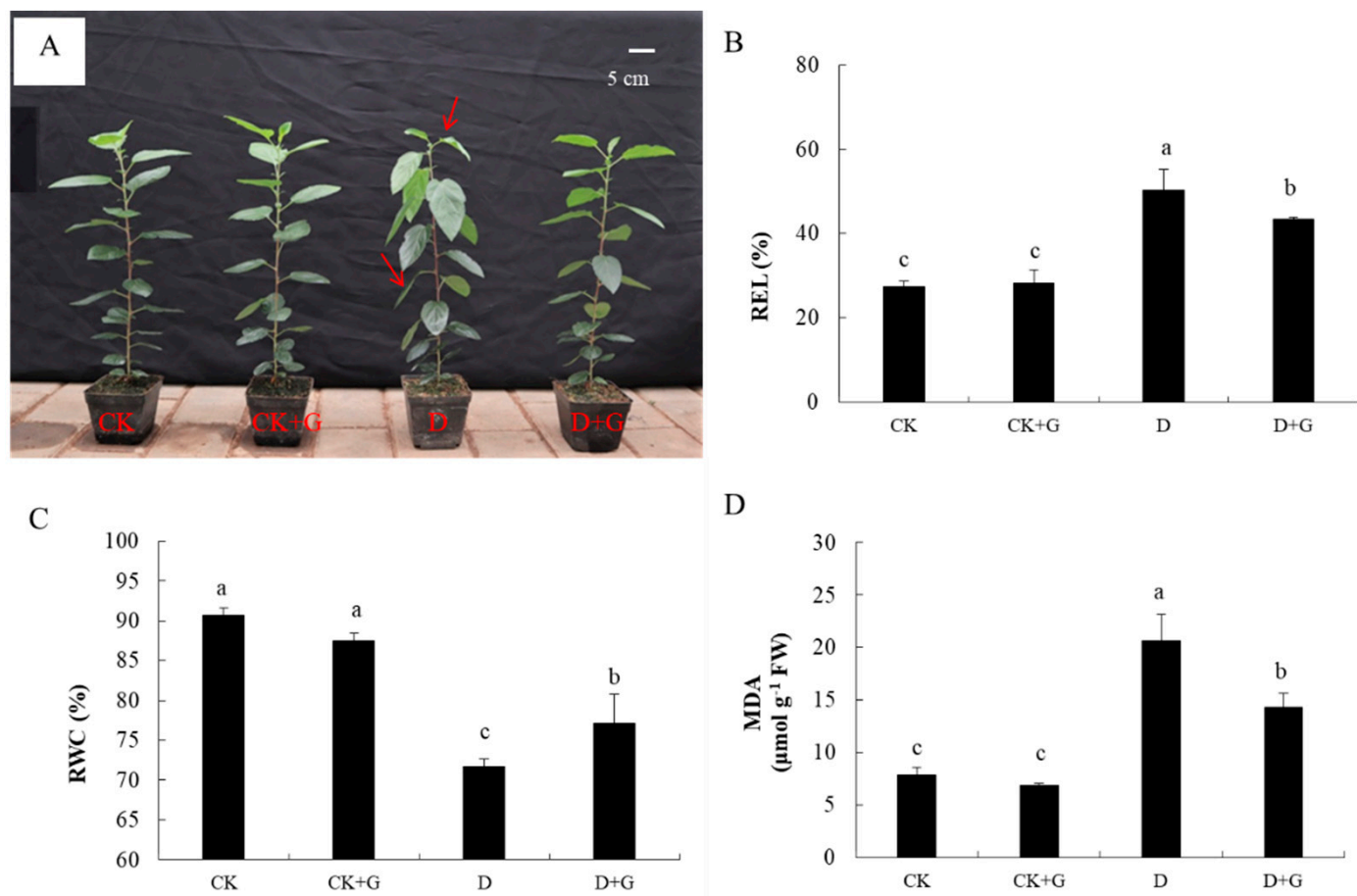

D

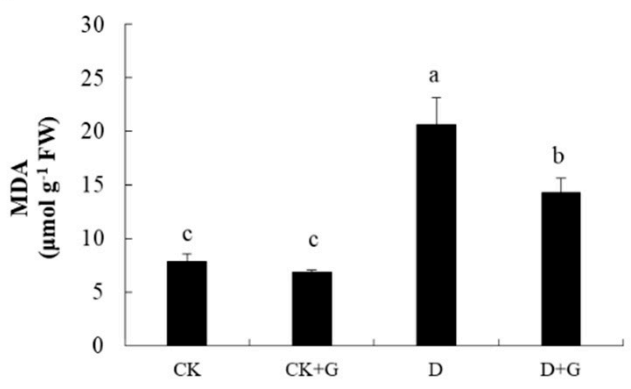

Figure 2. Phenotype of apple seedlings treated with $\gamma$-aminobutyric acid (GABA) application under drought stress for 15 days (A). CK: control; CK + G: control +0.5 mM GABA; D: drought stress; D + G: drought stress +0.5 mM GABA. The effects of GABA application on relative electrolyte leakage (REL, B), relative water content (RWC, C) and malondialdehyde content (MDA, D) of apple seedlings under drought stress for 15 days. Data are the mean $\pm \mathrm{SD}(\mathrm{n}=3$ ). Tukey's multiple range test (two-way) based on an analysis of variance (ANOVA) was utilized to analyze the data. Values with different letters are significantly different $(p<0.05)$.
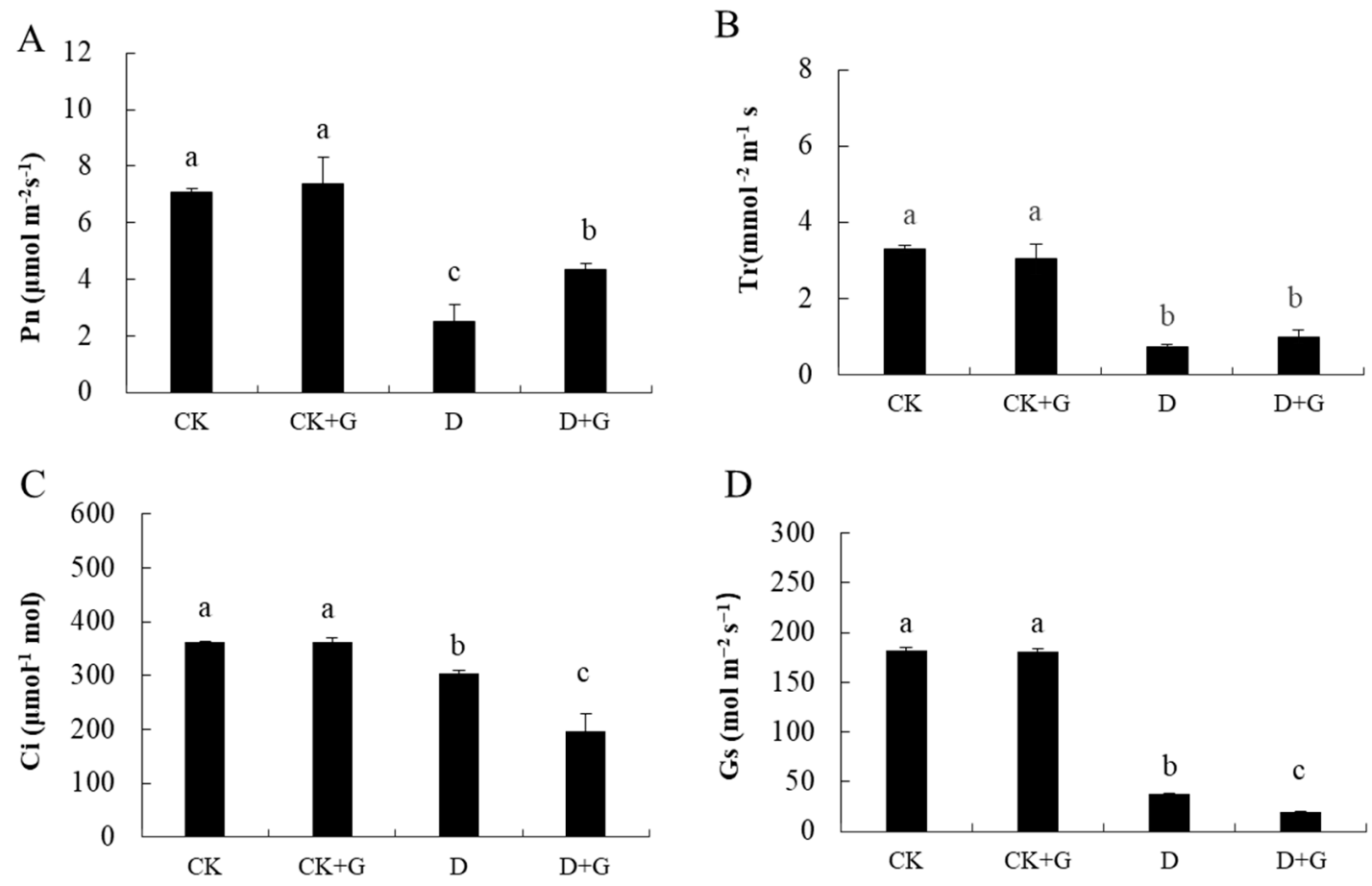

Figure 3. Effects of $\gamma$-aminobutyric acid (GABA) treatment on the photosynthetic rate (Pn, A), transpiration rate (Tr, B), intercellular $\mathrm{CO}_{2}$ concentration $(\mathrm{Ci}, \mathrm{C})$ and stomatal conductance $(\mathrm{Gs}, \mathrm{D})$ of apple seedlings subjected to drought stress for 15 days. Data are the mean $\pm S D(n=3)$. Tukey's multiple range test (two-way) based on an analysis of variance (ANOVA) was utilized to analyze the data. Values with different letters are significantly different $(p<0.05)$. 


\subsection{ROS Accumulation}

The contents of $\mathrm{H}_{2} \mathrm{O}_{2}$ and $\mathrm{O}_{2}{ }^{-}$and the activities of POD, SOD, and CAT were measured to reveal the accumulation of ROS in the leaves (Figure 4). The leaves of D + G treatment showed lower intensity when stained with NBT than the D leaves under drought stress (Figure $4 \mathrm{~A}$ ), indicating that $\mathrm{D}+\mathrm{G}$ accumulates less $\mathrm{O}_{2}{ }^{-}$than $\mathrm{D}$. The $\mathrm{CK}$ and $\mathrm{CK}+\mathrm{G}$ treatments had lower concentrations of $\mathrm{H}_{2} \mathrm{O}_{2}$ than the drought treatments. However, the $\mathrm{H}_{2} \mathrm{O}_{2}$ content of $\mathrm{D}+\mathrm{G}$ was $53 \%$ less than that of $\mathrm{D}$ (Figure $4 \mathrm{~B}$ ).
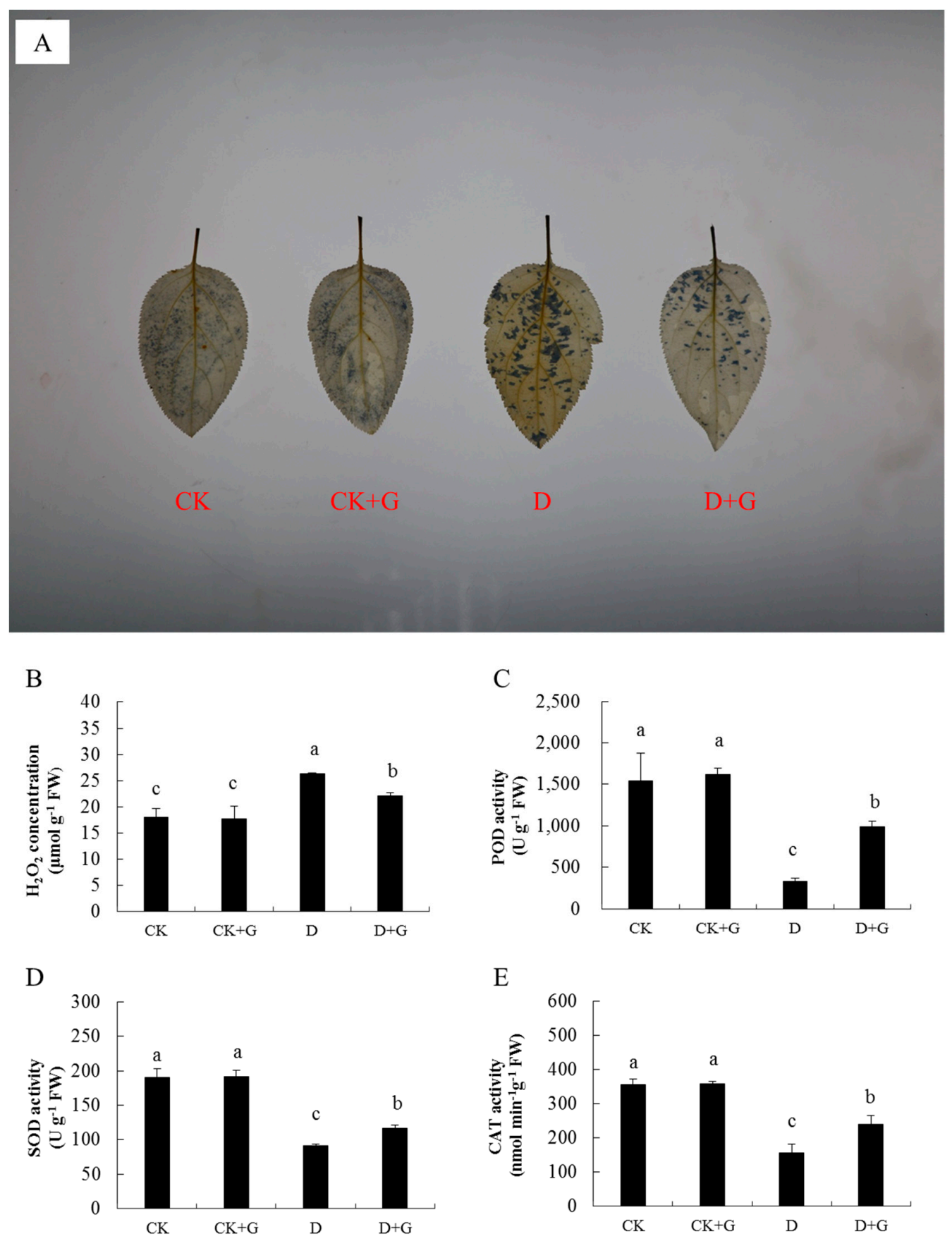

Figure 4. The effects of $\gamma$-aminobutyric acid (GABA) on the regulation of ROS level and antioxidant system under drought stress conditions. $\mathrm{O}_{2}{ }^{-}$accumulation in detached leaves using NBT staining (A). Effects of GABA application on hydrogen peroxide content $\left(\mathrm{H}_{2} \mathrm{O}_{2}, \mathbf{B}\right)$, peroxidase activity (POD, C), superoxide dismutase activity (SOD, D), and catalase activity (CAT, E) in the leaves of apple seedlings under drought stress for 15 days. Data are the mean \pm SD ( $n=3$ ). Tukey's multiple range test (two-way) based on an analysis of variance (ANOVA) was utilized to analyze the data. Values with different letters are significantly different $(p<0.05)$. 
Compared with the CK treatment, the activities of POD, SOD, and CAT decreased significantly in the D and D + G treatments. However, they were lower in D than those in $\mathrm{D}+\mathrm{G}$ by $66.8 \%, 22 \%$, and $34.6 \%$ respectively. There was no difference between the CK and $\mathrm{CK}+\mathrm{G}$ groups (Figure $4 \mathrm{C}-\mathrm{E}$ ). These results revealed that the exogenous GABA reduced the accumulation of ROS under drought stress.

\subsection{Effects of GABA on the Stomata}

Stomatal regulation is one of the important ways that plants manage a water deficit. The stomata open normally under $\mathrm{CK}$ and $\mathrm{CK}+\mathrm{G}$ conditions (Figure 5A). The stomatal opening decreased noticeably owing to drought stress. However, the stomatal conductance of $\mathrm{D}+\mathrm{G}$ was the smallest.
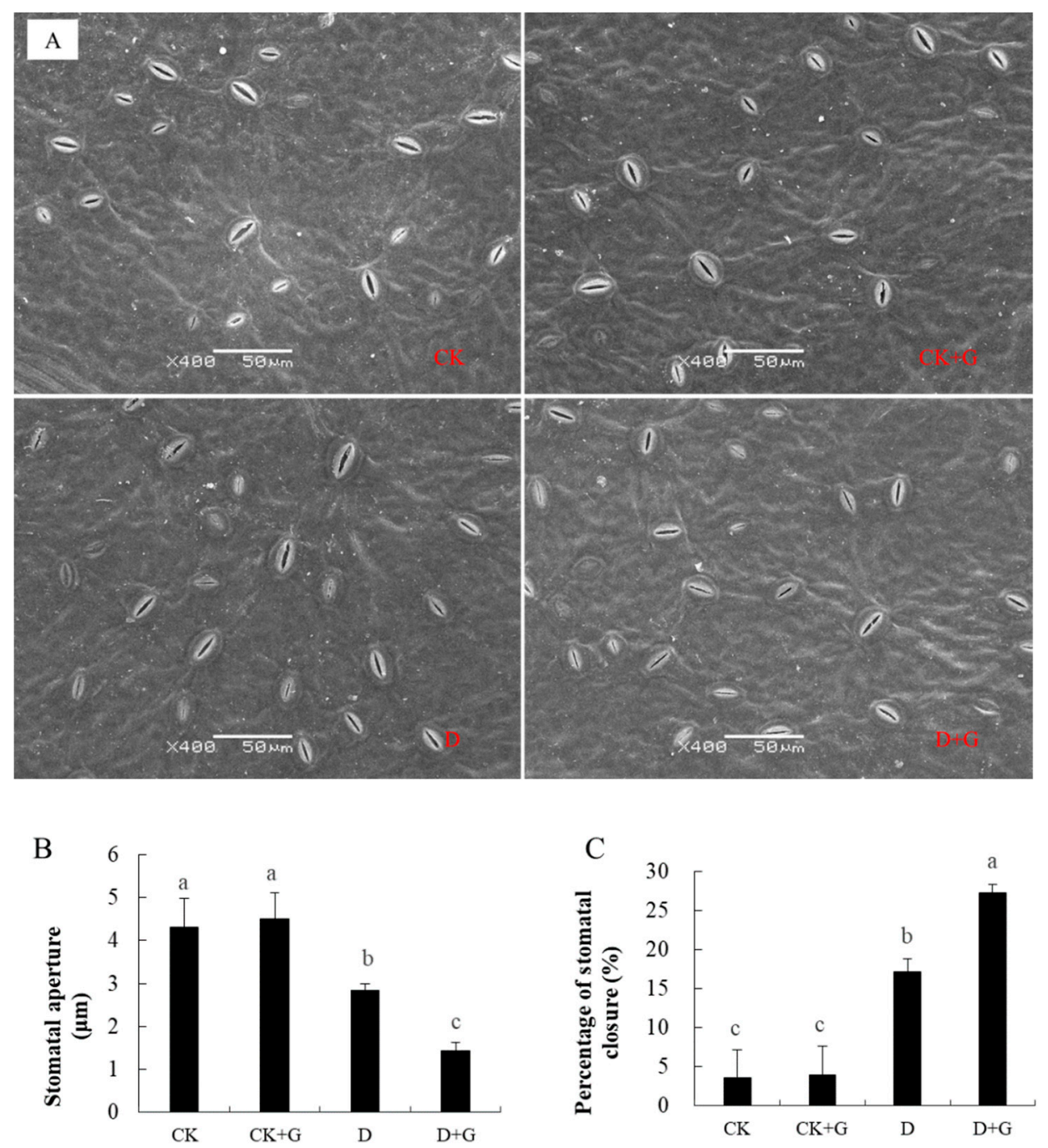

Figure 5. Stomatal behavior of plants after cultivation under well-watered and drought treatment conditions for 15 days. Stomatal guard cells of the plants were observed at the end of treatment via scanning electron microscopy (A). Stomatal aperture (B) and percentage of stomatal closure (C) were observed at the end of treatment. Data are the mean $\pm S D(n=3)$. Tukey's multiple range test (two-way) based on an analysis of variance (ANOVA) was utilized to analyze the data. Values with different letters are significantly different $(p<0.05)$.

The stomatal aperture of D was $0.03 \mu \mathrm{m}$, but it was $0.014 \mu \mathrm{m}$ in $\mathrm{D}+\mathrm{G}$ (Figure $5 \mathrm{~B})$. The percentage of stomatal closure of $D+G$ was higher than that of $D$ (Figure $5 C$ ), indicating that more stomata were closed in D $+G$. 


\subsection{GABA and $A B A$ Concentration and Gene Expression}

Stomatal closure is one of the most important physiological responses regulated by $\mathrm{ABA}$. Under the conditions of normal watering, there was no significant difference in the content of GABA and ABA between the $\mathrm{CK}$ and $\mathrm{CK}+\mathrm{G}$ groups. However, after 15 days of drought stress, compared with the $\mathrm{CK}$, the content of GABA and $\mathrm{ABA}$ in $\mathrm{D}$ and $\mathrm{D}+\mathrm{G}$ increased significantly. The content of GABA of $D+G$ was $17.8 \%$ higher than that of $D$ (Figure $6 \mathrm{~A}$ ), and the $\mathrm{ABA}$ content of $\mathrm{D}+\mathrm{G}$ was $36.8 \%$ higher than that of $\mathrm{D}$ (Figure $6 \mathrm{~B}$ ).


Figure 6. $\gamma$-aminobutyric acid (GABA) content of plants treated for 15 days (A). ABA content of plants treated for 15 days (B). Analysis of expression of ABA signaling-related genes and stress signaling genes in plants under well-watered and drought conditions (C-L). Tukey's multiple range test (two-way) based on analysis of variance (ANOVA) was utilized to analyze the data. Values with different letters are significantly different $(p<0.05)$. 
We also examined the expression of genes related to the ABA signaling pathway, and the expression of these genes increased significantly under drought compared with those under sufficient water conditions (Figure 6C-E,G-I). In addition, the expression of HAB1 decreased (Figure 6F). The results showed that compared with the CK, the levels of expression of PYL4, ABI1, ABI2, and OST1 increased under drought, and the level of expression of $A B F 3$ in $\mathrm{D}+\mathrm{G}$ was significantly higher than that in the $\mathrm{D}$ treatment.

In apple, some studies have also explored the involvement of these genes in stress signal transduction [35]. The expression of stress signaling genes, including $R D 22, R D 29 B$, and $L E A$, were studied. The results showed that the expression levels of these genes were increased after stress treatment, and the transcriptional levels were higher in D + G (Figure 6J-L).

\section{Discussion}

Under drought stress, plants usually display a decreased RWC, low turgor pressure, and a low transpiration rate [36], causing lipid peroxidation and the inactivation of enzymes. Drought stress induces osmotic and oxidative stresses that perturb plant metabolism and lead to membrane damage and the accumulation of lipid peroxides [2]. Our results showed that drought stress can increase the damage to cell membranes in apple seedlings. In accordance with previous findings of Coix lacryma-jobi L. and tomato [37,38], our results also indicated that drought stress significantly affected the activities of POD, SOD, and CAT accompanied by a rapid increase in active oxygen metabolites. However, exogenous GABA could reduce the accumulation of ROS, and the GABA content in plants increased significantly after stress, similar to the results of another study of white clover [39]. The study on white clover showed that exogenous application of GABA effectively alleviated drought-induced damage in leaves, inducing significantly higher relative water content, lower electrolyte leakage, lipid peroxidation, and leaf wilt. These results indicate the positive function of GABA in drought stress. Furthermore, the transcript levels of some drought-responsive genes, i.e., RD22, LEA, RD29B, and NCED3, were up-regulated by the addition of GABA. Those results are consistent with previous results, which showed that representative genes related to drought were up-regulated in Malus in response to drought stress are beneficial to stimulation of the anti-stress system, and enhance the stress tolerance in apple $[35,40,41]$.

Previous findings had implicated that GABA has a positive effect of enhancing plant tolerance to both abiotic and biotic stresses. As a signal substance or metabolite, GABA has an important effect on plant growth and abiotic stress resistance by regulating the $\mathrm{pH}$ of cytoplasm, serving as a temporary nitrogen pool, and inducing antioxidant responses [42]. Previous studies showed that $2 \mathrm{mg}$ L-1 GABA effectively alleviated drought and heat-induced stress in sunflower [43], and $0.5 \mathrm{mM}$ GABA exhibited a positive function in alleviating heat-induced chlorophyll loss and photoinhibition [24]. Some protective effects of GABA on plants have also been reported for maize plants [32], tomato (Solanum lycopersicum L.) [38], and creeping bentgrass [24]. Similar results have been obtained with drought-stressed white clover (Trifolium repens), in which the application of GABA reduced lipid peroxidation and increased the relative water content, thereby reversing the adverse effects of a water deficit [39]. In our current study, physiological analyses indicated that GABA at the concentration of $0.5 \mathrm{mM}$ could efficiently alleviate the REL and loss of RWC in plant leaves and maintain the normal state of growth. All of these reports, along with our current results, suggest that GABA priming mitigates the damage caused by stress.

In the case of drought stress, the photosynthesis of many plants is affected [24,37,43]. In a previous study, photosynthesis depended on the gas exchange of stomata and the effective water transport of xylem [44]. These results indicate that under conditions of water deficit, plants respond to drought stress by closing their stomata, thus preventing excess water loss in the leaf tissue, similar to a recent study on olive cultivars [45]. This practice indicates that in the case of water deficit, although stomatal conductance decreases, 
it can maintain the initial photosynthetic rate and maintain the plant's growth [46]. In the current study, when water was sufficient, there was little difference in the gas exchange parameters between the $\mathrm{CK}$ and $\mathrm{CK}+\mathrm{G}$. However, under drought stress, exogenous GABA decreased the stomatal conductance and transpiration rate of seedlings, water retention was increased, and photosynthesis was higher than that of group D. A recent study has shown that cytosolic GABA signals modulate stomatal opening, WUE, and drought resilience transduced through negative regulation of ALMT9 activity, and GABA's role appears to be that of fine-tuning stomatal aperture [47]. Higher levels of GABA have been associated with improved drought tolerance in many plant species, providing the available precursors for synthesis of proteins and secondary metabolites for stress defense $[33,48]$. We hypothesized that GABA is produced in the cytosol in times of stress, that GABA priming also induces production of GABA in plants as a plant signaling molecule, and that cytosolic GABA has a role of inhibition of stomatal closure.

Our results showed that stomatal aperture was reduced and water retention and enzyme activity were increased, maintaining a higher photosynthetic rate with GABA application. However, the increase in photosynthesis may be owing to a variety of reasons. Theoretically, at the leaf level, the carboxylation rate can be increased by increasing the concentration of catalytically active RUBISCO sites, improving the kinetic characteristics of the enzyme [49,50], or bypassing photorespiration [51]. Another option is to increase the diffusion conductance of $\mathrm{CO}_{2}$ from the substomatal cavity to the fixed part of mesophyll $(\mathrm{Gm})[52,53]$. However, $\mathrm{Gm}$ is a complex feature, involving different structural characteristics and molecular controls; therefore, it requires additional study before it can be utilized in the field.

A previous study found that when apple (Malus domestica) was under drought stress, ABA signaling transduction mediated stomatal regulation and a variety of ABA/stressrelated gene expression to cope with drought conditions [54]. Under drought stress, ABA synthesis increased significantly and was transported to the leaves through the xylem and phloem, entering the guard cells so that the stomata are closed and the evaporation of water is reduced [55]. ABA-mediated stomatal closure is the foremost response of plant to drought stress [54] and activates the genes related to the induction of drought resistance [4].

Since we observed that the stomatal conductance decreased significantly after shortterm drought, we measured the content of $\mathrm{ABA}$ in leaves to explore the reason for this decrease. Our results showed that $\mathrm{ABA}$ accumulates greatly in leaves, particularly in the $\mathrm{D}$ $+\mathrm{G}$ treatment (Figure $6 \mathrm{~B}$ ). The concentration of $\mathrm{ABA}$ increased in plant tissues to promote stomatal closure and avoid excessive water loss [56], demonstrating that GABA and ABA have a synergistic effect on stomatal closure.

The plant hormone abscisic acid (ABA) functions as a chemical signal in response to environmental stresses. When plants are subjected to stress, these stress signals are converted to ABA, and this triggers the activation of plant physiological and developmental processes, thereby inducing adaptation to the stress conditions $[57,58]$. Under drought stress, ABA synthesis increased significantly. ABA receptors, including PYR/PYPE, control ABA signal transduction by inhibiting PP2Cs $[13,59]$. PYL4 is a gene that encodes PYL receptors that have previously been shown to be responsive to drought stress [54]. In this research, the expression of these genes, ABI1, ABI2, OST1, ABF3, was induced by drought and was higher in D + G. Transcriptional levels of genes related to the ABA pathway were also consistent with the changes in ABA content. Previous findings have shown that the key molecules of PP2Cs in ABA signal transduction include $A B I 1, A B I 2$, and $H A B 1$ [18]. $H A B 1$ is a negative regulator of ABA signal transduction [60]. ABI1 regulates stomatal opening in Arabidopsis thaliana, and the stomatal opening of an abi1-1 ineffective mutant was significantly larger than that of the wild type [61]. The ABFs gene is a positive regulator of leaf senescence and overall survival induced by ABA [62]. Our results suggest that that GABA can participate in the ABA signaling pathway by controlling ABA levels, increasing the strength of other stress-responsive pathways to enhance the drought tolerance. Previous reports had indicated that GABA works in harmony with phytohormones and suggested 
that regulation of phytohormones by exogenous GABA could play a key role in reducing plant stress [33]. GABA may act as a signaling molecule and participates in regulating the expression of many genes including hormones and stress response [63]. These results indicate that the ABA signal path was activated under drought stress, especially in plants treated with GABA. We found that, in the presence of GABA, the production of ABA was increased under drought stress. Thus, it is likely that GABA helped improve drought tolerance by increasing the content of ABA in our plants and then enhanced tolerance to drought stress.

\section{Materials and Methods}

\subsection{Plant Material and Growth Conditions}

Apple plants were cultivated under greenhouse conditions in Yangling, Shaanxi province, China. M. hupehensis has apomixis characteristics. Its seedlings grew consistently. In this experiment, the seeds of $M$. hupehensis were collected at Pingyi in Shandong Province, China, and treated by stratification at $4{ }^{\circ} \mathrm{C}$ for approximately 40 days. They were then planted in plates that contained identical amounts of a mixture of perlite/vermiculite/peat $(1: 1: 6 \mathrm{v} / \mathrm{v} / \mathrm{v})$. During growth the seeds were watered every 4 days during their growth period to maintain soil moisture content at $65-75 \%$ field capacity. The light-exposure time was $14 \mathrm{~h}$ within a $24 \mathrm{~h}$ period, and the light intensity was 8000-9000 Lx. The average temperature was $26^{\circ} \mathrm{C}$. Deionized water was used to irrigate the seedlings and maintain the levels of soil moisture at $65-75 \%$ field capacity.

\subsection{Screening for Optimal GABA Concentrations}

Seven drought treatments were established to screen suitable concentrations of GABA. A total of 160 apple seedlings that were two months old were randomly divided into eight groups. The apple seedlings in group I were watered with deionized water every 4 days as the control to maintain the soil moisture content at $70-75 \%$ field capacity. The other six groups were designed as drought stressed and treated by deionized water that contained $0,0.25,0.5,1,2,5$, and $8 \mathrm{mM}$ of GABA, respectively, which were groups II, III, IV, V VI, VII, and VIII. The plants treated with GABA were watered at the same time as the control. After watering twice, irrigation was withheld from them to achieve natural water loss, primarily owing to soil evaporation and plant leaf transpiration, and thus induce drought stress. For each treatment, the leaves of the third to fifth leaves from the top (three replicates) were harvested after 15 days to detect the relative water content (RWC) and relative electrolyte leakage (REL). Each experiment was repeated independently three times.

\subsection{Drought Stress and Exogenous GABA Treatment}

To clarify the effect of GABA on apple seedlings under drought, we performed additional research after screening to determine the optimal concentration. When grown to 6-8 true leaves, the seedlings were replanted into plastic pots $(9.5 \mathrm{~cm}$ high and $10 \mathrm{~cm}$ in diameter), which were filled with a mixture of perlite/vermiculite/peat $(1: 1: 6 v / v / v)$ and weighed to $500 \mathrm{~g}$. After 50 days, 200 healthy seedlings were selected and divided into four groups, separately designated as CK, CK $+\mathrm{G}$, D, and D + G treatments. The plants of the $\mathrm{CK}$ and $\mathrm{D}$ treatments were watered with deionized water every 4 days. Moreover, the $\mathrm{CK}+\mathrm{G}$ and $\mathrm{D}+\mathrm{G}$ treatments were irrigated using deionized water with $0.5 \mathrm{mM}$ GABA. After the last watering, groups $D$ and $D+G$ were no longer watered. Each watering maintained the soil moisture at approximately $70-75 \%$ field capacity. The plant samples were harvested at 15 days after natural drought for physiological and biochemical analyses. At least 30 seedlings were harvested for each treatment. Each experiment consisted of three independent biological replicates. 


\subsection{Gas Exchange Measurements}

After 15 days of drought treatments, the fifth leaf was selected to measure leaf gas exchange. The photosynthetic rate $\left(\mathrm{Pn}, \mu \mathrm{mol} \mathrm{m}^{-2} \mathrm{~s}^{-1}\right)$, stomatal conductance (Gs, mol m$\left.{ }^{-2} \mathrm{~s}^{-1}\right)$, intercellular $\mathrm{CO}_{2}$ concentration $\left(\mathrm{Ci}, \mu \mathrm{mol} \mathrm{mol}^{-1}\right)$, and transpiration rate $(\mathrm{Tr}$, mmol m${ }^{-1} \mathrm{~s}^{-1}$ ) were measured using an open gas exchange system (CIRAS-3, PP-system, Hitchin, UK) between 14:00-16:00 on a sunny day. The $\mathrm{CO}_{2}$ concentration and photosynthetic photon flux density in the leaf chamber were maintained at $400 \mathrm{ppm}$ and $1200 \mathrm{~mol}$ photons $\mathrm{m}^{-2} \mathrm{~s}^{-1}$, respectively. Twenty plants in each treatment were selected randomly.

\subsection{RWC, REL, and MDA of Leaves}

The relative electrolyte leakage (REL) was determined as previously described [29]. The relative water content (RWC) was determined gravimetrically and calculated as follows: RWC $=[(\mathrm{FM}-\mathrm{DM}) /(\mathrm{TM}-\mathrm{DM})] \times 100 \%$. On the 15 th day of drought, the fresh weight $(\mathrm{FW})$ and the dry mass $(\mathrm{DM})$ of leaves from each treatment were measured. The turgid mass (TM) was recorded after the fresh leaves were soaked in distilled water for $24 \mathrm{~h}$ in a closed container at $4{ }^{\circ} \mathrm{C}$ in the dark. Ten leaves were collected for each treatment, and this was repeated three times. The malondialdehyde (MDA) content was measured using the TBA method as previously described [64].

\subsection{Detection of Antioxidant Enzyme Activities and NBT}

On the 15th day, mature leaves were gently cleaned, soaked in NBT, placed in the dark for $4 \mathrm{~h}$, and finally decolorized with $85 \%$ anhydrous ethanol. NBT staining was used to detect the content of superoxide anions $\left(\mathrm{O}_{2}{ }^{-}\right)$. The concentration of $\mathrm{H}_{2} \mathrm{O}_{2}$ was detected using a plant $\mathrm{H}_{2} \mathrm{O}_{2}$ extraction kit (Sangon Biotech, Shanghai, China).

A total of $0.1 \mathrm{~g}$ of leaves was used to detect the activities of antioxidant enzymes. The activities of SOD, POD, and CAT were detected by plant SOD, POD, and CAT extraction kits (Sangon Biotech, Shanghai, China) following the manufacturer's instructions.

\subsection{Concentrations of $G A B A$ and $A B A$}

GABA was extracted and measured as described by Jin et al. [65]. Liquid chromatographymass spectrometry (LC-MS) was conducted (LC: AC, ExionLC; MS:Q-trap5500, AB Sciex, Framingham, MA, USA). ABA was extracted as described by Müller and Munné-Bosch [66]. The details are as follows: The ABA extract was configured based on the volume ratio of methanol, isopropanol, and acetic acid at 20:79:1 and precooled at $-20^{\circ} \mathrm{C}$. A total of $100 \mathrm{mg}$ frozen leaves was weighed, and the ABA extract was added and ground to a homogenate in a mortar and swirled for $5 \mathrm{~min}$. The homogenates were centrifuged at 12,000 rpm for $24 \mathrm{~h}$ at $4{ }^{\circ} \mathrm{C}$. The supernatant was carefully transferred to a clean $2 \mathrm{~mL}$ centrifuge tube. A volume of $500 \mu \mathrm{L}$ of extract was added to the remaining precipitates and fully swirled for $5 \mathrm{~min}$. The supernatant was extracted twice, and all the supernatants were filtered with a 0.22 um filter membrane. The content of ABA was determined using an LC: AC, ExionLC; MS:Q-trap5500, AB Sciex.

\subsection{Observation of the Stomata in the Leaves}

The stomata were observed using SEM, and the samples were treated as follows: On the 15th day of treatment, 10 leaves were randomly taken, cut into a square with a side length of $4 \mathrm{~mm}$, immediately placed in $4 \%$ glutaraldehyde, pumped with a vacuum pump for $30 \mathrm{~min}$, placed at $4{ }^{\circ} \mathrm{C}$ for more than $6 \mathrm{~h}$, and rinsed five times with $0.2 \mathrm{M}$ PBS buffer ( $\mathrm{pH}$ 6.8) for 5, 10, 15, 20, and $30 \mathrm{~min}$, respectively. The samples were dehydrated with $30 \%$, $50 \%$, and 70\% ethanol for $15 \mathrm{~min}$ and then with $80 \%, 90 \%$, and $100 \%$ ethanol for $30 \mathrm{~min}$ and rinsed twice with isoamyl acetate for 25 min each. The samples were dried using a Hitachi HCP-2 zero boundary point dryer (Tokyo, Japan), and gold was sprayed after drying. The samples were observed and photographed under SEM. Each treatment examined 20 fields of vision. The stomatal aperture was measured using Image J (NIH, Bethesda, MD, USA). 
Percentage of stomatal closure $(\%)=$ number of stomata closed per visual field/number of stomata per visual field $\times 100 \%$.

\section{9. qRT-PCR Analysis}

The total RNA of all samples was extracted using a TIANGEN Plant Total RNA isolation Kit Plus (TIANGEN Biotech Co., Ltd., Beijing, China) according to the manufacturer's instructions. Quantitative real-time PCR (qRT-PCR) was performed on an ABI StepOnePlus real-time PCR system (Applied Biosystems, Singapore, Singapore) using a SYBR Premix Ex TaqII (TaKaRa, Kyoto, Japan). MdActin was used as the internal control and was simultaneously amplified [67]. The relative level of expression of these genes was calculated using the $2^{-\Delta \Delta C T}$ method [68]. Three independent biological replications were performed per sample. The sequence of primers used in the experiment is shown in Table 1.

Table 1. Gene information and primers used for real-time quantitative PCR.

\begin{tabular}{cc}
\hline Primer Names & Sequences \\
\hline RT-PYL4-F & CGGCGTCGTCGCAGTACCAA \\
RT-PYL4-R & TCCTGAGTCACGGCGGAGCA \\
RT-ABI1-F & GGGAGGAACAACAAGGGA \\
RT-ABI-R & AAGAAATGAACGGGTGAGAT \\
RT-ABI2-F & GACGACGAATGCCTAATT \\
RT-ABI-R & TCTTGTGCCAGAGGAGTA \\
RT-HAB1-F & ACCCACCTAACCAGTCAC \\
RT-HAB1-R & ACCATAATCCCATCACCT \\
RT-OST1-F & AGCACCTGAAGTCCTATC \\
RT-OST1-R & ACTAAGAATCCGCCCAAT \\
RT-ABF3-F & AATGCTCAGTTGGGTAGTCC \\
RT-ABF3-R & TTCGCAGGTGAAGGCGTC \\
RT-NCED3-F & GCAGGAGATGATCGGCG \\
RT-NCED3-R & CAGAAGCAGTCGGGGCAGT \\
RT-RD22-F & GACATGCGTCCTGGAACAAC \\
RT-RD22-R & ATTTCTGGCAGCTTGTTGG \\
RT-RD29B-F & TGTGACAGGCGGTGAAGAAAT \\
RT-RD29B-R & TCAGCGATAGCGGAAGTGG \\
RT-LEA-F & TGGGGGAGATGACTTGGAG \\
RT-LEA-R & CTGCTTCAGGTGTAGAAGC \\
MdActin-F & TGACCGAATGAGCAAGGAAATTACT \\
MdActin-R & TACTCAGCTTTGGCAATCCACATC \\
\hline
\end{tabular}

\subsection{Statistical Analysis}

All the data were statistically analyzed using Microsoft Excel 2010 (Redmond, WA, USA) and SPSS 21.0 (IBM, Inc., Armonk, NY, USA) ( $p<0.05)$. Tukey's multiple range test (two-way) based on an analysis of variance (ANOVA) was utilized to analyze the data.

\section{Conclusions}

The results showed that treatment with exogenous GABA $(0.5 \mathrm{mM})$ could effectively alleviate drought stress. GABA could induce apple seedlings to accumulate a large amount of ABA to activate the ABA signal pathway, resulting in stomatal closure, which ensured that the plant leaves could reduce water loss under drought conditions. This study shows that exogenous GABA could promote stomatal closure by increasing the accumulation of $\mathrm{ABA}$ and the subsequent drought tolerance of apple seedlings under drought conditions.

Author Contributions: C.L. (Chenlu Liu) and C.L. (Cuiying Li) conceived and designed the experiments; C.L. (Chenlu Liu) performed the experiments with assistance from H.W., X.Z., T.G. and C.L. (Chenlu Liu) analyzed the data; C.L. (Chenlu Liu) wrote the paper; C.L. (Cuiying Li) provided financial support and helped perform the analysis with constructive discussions; F.M. provided materials and laboratory apparatus. All authors have read and agreed to the published version of the manuscript. 
Funding: This research was funded by [Major Science and Technology Project of Shaanxi Province] grant number [2020zdzx03-01-01], and by [Basic Research Plan of Natural Science of Shaanxi Province] grant number [2021JM-103].

Conflicts of Interest: The authors declare that there are no conflicts of interest.

$\begin{array}{ll}\text { Abbreviations } \\ \text { GABA } & \gamma \text {-aminobutyric acid } \\ \text { ABA } & \text { abscisic acid } \\ \text { WUE } & \text { water use efficiency } \\ \text { SOD } & \text { superoxide dismutase } \\ \text { POD } & \text { peroxidase } \\ \text { CAT } & \text { catalase } \\ \text { MDA } & \text { malondialdehyde } \\ \text { RWC } & \text { relative water content } \\ \text { REL } & \text { relative electrolyte leakage }\end{array}$

\section{References}

1. Guo, Z.; Du, N.; Li, Y.; Zheng, S.; Shen, S.; Piao, F. Gamma-aminobutyric acid enhances tolerance to iron deficiency by stimulating auxin signaling in cucumber (Cucumis sativus L.). Ecotoxicol. Environ. Saf. 2020, 192, 110285. [CrossRef]

2. Li, P.; Zhu, Y.; Song, X.; Song, F. Negative effects of long-term moderate salinity and short-term drought stress on the photosynthetic performance of Hybrid Pennisetum. Plant Physiol. Biochem. 2020, 155, 93-104. [CrossRef]

3. Ding, H.; Qian, Y.; Fang, Y.; Ji, Y.; Sheng, J.; Ge, C. Characteristics of SlCML39, a Tomato Calmodulin-like Gene, and Its Negative Role in High Temperature Tolerance of Arabidopsis thaliana during Germination and Seedling Growth. Int. J. Mol. Sci. 2021, 22, 11479. [CrossRef] [PubMed]

4. Zhu, J. Abiotic Stress Signaling and Responses in Plants. Cell 2016, 167, 313-324. [CrossRef]

5. Sahin, U.; Ekinci, M.; Ors, S.; Turan, M.; Yildiz, S.; Yildirim, E. Effects of individual and combined effects of salinity and drought on physiological, nutritional and biochemical properties of cabbage (Brassica oleracea var. capitata). Sci. Hortic. 2018, 240, 196-204. [CrossRef]

6. Kaya, M.D.; Okçu, G.; Atak, M.; Çıkılı, Y.; Kolsarıcı, Ö. Seed treatments to overcome salt and drought stress during germination in sunflower (Helianthus annuus L.). Eur. J. Agron. 2006, 24, 291-295. [CrossRef]

7. Wilkinson, S.; Davies, W.J. ABA-based chemical signalling: The co-ordination of responses to stress in plants. Plant Cell Environ. 2002, 25, 195-210. [CrossRef] [PubMed]

8. Merewitz, E.B.; Du, H.; Yu, W.; Liu, Y.; Gianfagna, T.; Huang, B. Elevated cytokinin content in ipt transgenic creeping bentgrass promotes drought tolerance through regulating metabolite accumulation. J. Exp. Bot. 2011, 63, 1315-1328. [CrossRef]

9. Acharya, B.R.; Assmann, S.M. Hormone interactions in stomatal function. Plant Mol. Biol. 2009, 69, 451-462. [CrossRef]

10. Wilkinson, S.; Kudoyarova, G.R.; Veselov, D.S.; Arkhipova, T.N.; Davies, W.J. Plant hormone interactions: Innovative targets for crop breeding and management. J. Exp. Bot. 2012, 63, 3499-3509. [CrossRef]

11. Buckley, T.N. How do stomata respond to water status? New Phytol. 2019, 224, 21-36. [CrossRef]

12. Dodd, I.C. Abscisic acid and stomatal closure: A hydraulic conductance conundrum? New Phytol. 2013, 197, 6-8. [CrossRef] [PubMed]

13. Park, S.-Y.; Fung, P.; Nishimura, N.; Jensen, D.R.; Fujii, H.; Zhao, Y.; Lumba, S.; Santiago, J.; Rodrigues, A.; Chow, T.-F.F.; et al. Abscisic Acid Inhibits Type 2C Protein Phosphatases via the PYR/PYL Family of START Proteins. Science 2009, 324, 1068-1071. [CrossRef] [PubMed]

14. Schweighofer, A.; Hirt, H.; Meskiene, I. Plant PP2C phosphatases: Emerging functions in stress signaling. Trends Plant Sci. 2004, 9 , 236-243. [CrossRef] [PubMed]

15. Fujita, Y.; Nakashima, K.; Yoshida, T.; Katagiri, T.; Kidokoro, S.; Kanamori, N.; Umezawa, T.; Fujita, M.; Maruyama, K.; Ishiyama, K.; et al. Three SnRK2 Protein Kinases are the Main Positive Regulators of Abscisic Acid Signaling in Response to Water Stress in Arabidopsis. Plant Cell Physiol. 2009, 50, 2123-2132. [CrossRef] [PubMed]

16. Choi, H.-I.; Hong, J.-H.; Ha, J.-O.; Kang, J.-Y.; Kim, S.Y. ABFs, a Family of ABA-responsive Element Binding Factors. J. Biol. Chem. 2000, 275, 1723-1730. [CrossRef]

17. Li, J.; Wang, X.-Q.; Watson, M.B.; Assmann, S.M. Regulation of Abscisic Acid-Induced Stomatal Closure and Anion Channels by Guard Cell AAPK Kinase. Science 2000, 287, 300-303. [CrossRef]

18. Santiago, J.; Rodrigues, A.; Saez, A.; Rubio, S.; Antoni, R.; Dupeux, F.; Park, S.-Y.; Márquez, J.A.; Cutler, S.R.; Rodriguez, P.L. Modulation of drought resistance by the abscisic acid receptor PYL5 through inhibition of clade A PP2Cs. Plant J. 2009, 60, 575-588. [CrossRef]

19. Leng, P.; Yuan, B.; Guo, Y. The role of abscisic acid in fruit ripening and responses to abiotic stress. J. Exp. Bot. 2013, 65, 4577-4588. [CrossRef] 
20. Xie, X.; Wang, Y.; Williamson, L.; Holroyd, G.H.; Tagliavia, C.; Murchie, E.; Theobald, J.; Knight, M.; Davies, W.J.; Leyser, O.; et al. The Identification of Genes Involved in the Stomatal Response to Reduced Atmospheric Relative Humidity. Curr. Biol. 2006, 16, 882-887. [CrossRef]

21. Steward, F.C.; Thompson, J.F.; Dent, C.E. $\gamma$-Aminobutyric acid: A constituent of the potato tuber? Science 1949, 110, 439-440.

22. Bouché, N.; Fromm, H. GABA in plants: Just a metabolite? Trends Plant Sci. 2004, 9, 110-115. [CrossRef]

23. Shelp, B.J.; Bown, A.W.; Zarei, A. 4-Aminobutyrate (GABA): A metabolite and signal with practical significance. Botany 2017, 95, 1015-1032. [CrossRef]

24. Li, Z.; Yu, J.; Peng, Y.; Huang, B. Metabolic pathways regulated by $\gamma$-aminobutyric acid (GABA) contributing to heat tolerance in creeping bentgrass (Agrostis stolonifera). Sci. Rep. 2016, 6, 30338. [CrossRef] [PubMed]

25. Hasan, M.; Alabdallah, N.M.; Alharbi, B.M.; Waseem, M.; Yao, G.; Liu, X.-D.; El-Gawad, H.G.A.; El-Yazied, A.A.; Ibrahim, M.F.M.; Jahan, M.S.; et al. GABA: A Key Player in Drought Stress Resistance in Plants. Int. J. Mol. Sci. 2021, 22, 10136. [CrossRef] [PubMed]

26. Renault, H.; Roussel, V.; El Amrani, A.; Arzel, M.; Renault, D.; Bouchereau, A.; Deleu, C. The Arabidopsis pop2-1mutant reveals the involvement of GABA transaminase in salt stress tolerance. BMC Plant Biol. 2010, 10, 20. [CrossRef] [PubMed]

27. Ma, Y.; Wang, P.; Chen, Z.; Gu, Z.; Yang, R. GABA enhances physio-biochemical metabolism and antioxidant capacity of germinated hulless barley under $\mathrm{NaCl}$ stress. J. Plant Physiol. 2018, 231, 192-201. [CrossRef]

28. Vijayakumari, K.; Puthur, J.T. $\gamma$-Aminobutyric acid (GABA) priming enhances the osmotic stress tolerance in Piper nigrum Linn. plants subjected to PEG-induced stress. Plant Growth Regul. 2016, 78, 57-67. [CrossRef]

29. Rezaie-Chiyaneh, E.; Seyyedi, S.M.; Ebrahimian, E.; Moghaddam, S.S.; Damalas, C.A. Exogenous application of gammaaminobutyric acid (GABA) alleviates the effect of water deficit stress in black cumin (Nigella sativa L.). Ind. Crop. Prod. 2018, 112, 741-748. [CrossRef]

30. Li, Y.; Liu, C.; Sun, X.; Liu, B.; Zhang, X.; Liang, W.; Huo, L.; Wang, P.; Ma, F.; Li, C. Overexpression of MdATG18a enhances alkaline tolerance and GABA shunt in apple through increased autophagy under alkaline conditions. Tree Physiol. 2020, 40, 1509-1519. [CrossRef]

31. Li, Z.; Zeng, W.; Cheng, B.; Huang, T.; Peng, Y.; Zhang, X. $\gamma$-Aminobutyric Acid Enhances Heat Tolerance Associated with the Change of Proteomic Profiling in Creeping Bentgrass. Molecules 2020, 25, 4270. [CrossRef] [PubMed]

32. Seifikalhor, M.; Aliniaeifard, S.; Bernard, F.; Seif, M.; Latifi, M.; Hassani, B.; Didaran, F.; Bosacchi, M.; Rezadoost, H.; Li, T. $\gamma$ Aminobutyric acid confers cadmium tolerance in maize plants by concerted regulation of polyamine metabolism and antioxidant defense systems. Sci. Rep. 2020, 10, 3356. [CrossRef]

33. Hijaz, F.; Nehela, Y.; Killiny, N. Application of gamma-aminobutyric acid increased the level of phytohormones in Citrus sinensis. Planta 2018, 248, 909-918. [CrossRef]

34. Ji, J.; Yue, J.; Xie, T.; Chen, W.; Du, C.; Chang, E.; Chen, L.; Jiang, Z.; Shi, S. Roles of $\gamma$-aminobutyric acid on salinity-responsive genes at transcriptomic level in poplar: Involving in abscisic acid and ethylene-signalling pathways. Planta 2018, 248, 675-690. [CrossRef] [PubMed]

35. Chen, K.; Song, M.; Guo, Y.; Liu, L.; Xue, H.; Dai, H.; Zhang, Z. MdMYB46 could enhance salt and osmotic stress tolerance in apple by directly activating stress-responsive signals. Plant Biotechnol. J. 2019, 17, 2341-2355. [CrossRef]

36. Tahi, H.; Wahbi, S.; Wakrim, R.; Aganchich, B.; Serraj, R.; Centritto, M. Water relations, photosynthesis, growth and water-use efficiency in tomato plants subjected to partial rootzone drying and regulated deficit irrigation. Plant Biosyst. 2007, 141, 265-274. [CrossRef]

37. Ferreira, R.A.; Borella, J.; Hüther, C.M.; Do Canto, A.C.B.; Correa, N.P.D.C.; Correia, D.M.; Borges, R.P.; De Pinho, C.F.; Machado, T.D.B.; Pereira, N. Drought-induced stress in leaves of Coix lacryma-jobi L. under exogenous application of proline and GABA amino acids. Braz. J. Bot. 2020, 43, 513-521. [CrossRef]

38. Wu, X.; Jia, Q.; Ji, S.; Gong, B.; Li, J.; Lü, G.; Gao, H. Gamma-aminobutyric acid (GABA) alleviates salt damage in tomato by modulating $\mathrm{Na}+$ uptake, the GAD gene, amino acid synthesis and reactive oxygen species metabolism. BMC Plant Biol. 2020, 20, 1-21. [CrossRef] [PubMed]

39. Yong, B.; Xie, H.; Li, Z.; Li, Y.-P.; Zhang, Y.; Nie, G.; Zhang, X.-Q.; Ma, X.; Huang, L.-K.; Yan, Y.-H.; et al. Exogenous Application of GABA Improves PEG-Induced Drought Tolerance Positively Associated with GABA-Shunt, Polyamines, and Proline Metabolism in White Clover. Front. Physiol. 2017, 8, 1107. [CrossRef]

40. Li, C.; Liang, B.; Chang, C.; Wei, Z.; Zhou, S.; Ma, F. Exogenous melatonin improved potassium content in Malus under different stress conditions. J. Pineal Res. 2016, 61, 218-229. [CrossRef]

41. He, L.; Li, L.; Zhu, Y.; Pan, Y.; Zhang, X.; Han, X.; Li, M.; Chen, C.; Li, H.; Wang, C. BolTLP1, a Thaumatin-like Protein Gene, Confers Tolerance to Salt and Drought Stresses in Broccoli (Brassica oleracea L. var. Italica). Int. J. Mol. Sci. 2021, $22,11132$. [CrossRef]

42. Fait, A.; Fromm, H.; Walter, D.; Galili, G.; Fernie, A.R. Highway or byway: The metabolic role of the GABA shunt in plants. Trends Plant Sci. 2008, 13, 14-19. [CrossRef]

43. Razik, E.S.A.; Alharbi, B.M.; Pirzadah, T.B.; Alnusairi, G.S.H.; Soliman, M.H.; Hakeem, K.R. $\gamma$-Aminobutyric acid (GABA) mitigates drought and heat stress in sunflower (Helianthus annuus L.) by regulating its physiological, biochemical and molecular pathways. Physiol. Plant. 2021, 172, 505-527. [CrossRef] 
44. Dodd, I.C.; Ferguson, B.J.; Beveridge, C.A. Apical Wilting and Petiole Xylem Vessel Diameter of the rms2 Branching Mutant of Pea are Shoot Controlled and Independent of a Long-Distance Signal Regulating Branching. Plant Cell Physiol. 2008, 49, 791-800. [CrossRef]

45. Bosabalidis, A.M.; Kofidis, G. Comparative effects of drought stress on leaf anatomy of two olive cultivars. Plant Sci. 2002, 163, 375-379. [CrossRef]

46. Silva, M.; Rubilar, R.; Espinoza, J.; Yanez, M.; Emhart, V.; Quiroga, J.J. Gas-exchange response and survival of young eucalyptus spp commercial genotypes under water stress. Bosque 2017, 38, 79-87. [CrossRef]

47. Xu, B.; Long, Y.; Feng, X.; Zhu, X.; Sai, N.; Chirkova, L.; Betts, A.; Herrmann, J.; Edwards, E.J.; Okamoto, M.; et al. GABA signalling modulates stomatal opening to enhance plant water use efficiency and drought resilience. Nat. Commun. 2021, 12, 1952. [CrossRef] [PubMed]

48. Khan, M.I.R.; Jalil, S.U.; Chopra, P.; Chhillar, H.; Ferrante, A.; Khan, N.A.; Ansari, M.I. Role of GABA in plant growth, development and senescence. Plant Gene 2021, 26, 100283. [CrossRef]

49. Galmés, J.; Conesa, M.À.; Ochogavía, J.M.; Perdomo, J.A.; Francis, D.M.; Ribas-Carbó, M.; Savé, R.; Flexas, J.; Medrano, H.; Cifre, J. Physiological and morphological adaptations in relation to water use efficiency in Mediterranean accessions of Solanum lycopersicum. Plant Cell Environ. 2011, 34, 245-260. [CrossRef] [PubMed]

50. Whitney, S.M.; Houtz, R.L.; Alonso, H. Advancing Our Understanding and Capacity to Engineer Nature's CO2-Sequestering Enzyme, Rubisco. Plant Physiol. 2011, 155, 27-35. [CrossRef]

51. Kebeish, R.; Niessen, M.; Thiruveedhi, K.; Bari, R.; Hirsch, H.-J.; Rosenkranz, R.; Stäbler, N.; Schönfeld, B.; Kreuzaler, F.; Peterhänsel, C. Chloroplastic photorespiratory bypass increases photosynthesis and biomass production in Arabidopsis thaliana. Nat. Biotechnol. 2007, 25, 593-599. [CrossRef]

52. Parry, M.A.J.; Flexas, J.; Medrano, H. Prospects for crop production under drought: Research priorities and future directions. Ann. Appl. Biol. 2005, 147, 211-226. [CrossRef]

53. Flexas, J.; Medrano, H. Drought-inhibition of photosynthesis in C3 plants: Stomatal and non-stomatal limitations revisited. Ann. Bot. 2002, 89, 183-189. [CrossRef] [PubMed]

54. Tan, Y.; Li, M.; Yang, Y.; Sun, X.; Wang, N.; Liang, B.; Ma, F. Overexpression of MpCYS4, A Phytocystatin Gene from Malus prunifolia (Willd.) Borkh., Enhances Stomatal Closure to Confer Drought Tolerance in Transgenic Arabidopsis and Apple. Front. Plant Sci. 2017, 8, 33. [CrossRef] [PubMed]

55. Raghavendra, A.S.; Gonugunta, V.K.; Christmann, A.; Grill, E. ABA perception and signalling. Trends Plant Sci. 2010, 15, 395-401. [CrossRef]

56. Saradadevi, R.; Palta, J.; Siddique, K. ABA-Mediated Stomatal Response in Regulating Water Use during the Development of Terminal Drought in Wheat. Front. Plant Sci. 2017, 8, 1251. [CrossRef] [PubMed]

57. Lim, C.W.; Baek, W.; Jung, J.; Kim, J.-H.; Lee, S.C. Function of ABA in Stomatal Defense against Biotic and Drought Stresses. Int. J. Mol. Sci. 2015, 16, 15251-15270. [CrossRef]

58. Finkelstein, R.R.; Gampala, S.S.L.; Rock, C.D. Abscisic Acid Signaling in Seeds and Seedlings. Plant Cell 2002, 14, S15-S45. [CrossRef]

59. Cutler, S.R.; Rodriguez, P.L.; Finkelstein, R.R.; Abrams, S.R. Abscisic Acid: Emergence of a Core Signaling Network. Annu. Rev. Plant Biol. 2010, 61, 651-679. [CrossRef] [PubMed]

60. Saez, A.; Apostolova, N.; Gonzalez-Guzman, M.; Gonzalez-Garcia, M.P.; Nicolas, C.; Lorenzo, O.; Rodriguez, P.L. Gain-of-function and loss-of-function phenotypes of the protein phosphatase 2C HAB1 reveal its role as a negative regulator of abscisic acid signalling. Plant J. 2004, 37, 354-369. [CrossRef]

61. Leung, J.; Bouvier-Durand, M.; Morris, P.-C.; Guerrier, D.; Chefdor, F.; Giraudat, J. Arabidopsis ABA Response Gene ABI1: Features of a Calcium-Modulated Protein Phosphatase. Science 1994, 264, 1448-1452. [CrossRef]

62. Zhao, Y.; Chan, Z.; Gao, J.; Xing, L.; Cao, M.; Yu, C.; Hu, Y.; You, J.; Shi, H.; Zhu, Y.; et al. ABA receptor PYL9 promotes drought resistance and leaf senescence. Proc. Natl. Acad. Sci. USA 2016, 113, 1949-1954. [CrossRef] [PubMed]

63. Shi, S.-Q.; Shi, Z.; Jiang, Z.-P.; Qi, L.-W.; Sun, X.-M.; Li, C.-X.; Liu, J.-F.; Xiao, W.-F.; Zhang, S.-G. Effects of exogenous GABA on gene expression ofCaragana intermediaroots under $\mathrm{NaCl}$ stress: Regulatory roles for $\mathrm{H} 2 \mathrm{O} 2$ and ethylene production. Plant Cell Environ. 2010, 33, 149-162. [CrossRef] [PubMed]

64. Jiao, X.; Li, Y.; Zhang, X.; Liu, C.; Liang, W.; Li, C.; Ma, F.; Li, C. Exogenous Dopamine Application Promotes Alkali Tolerance of Apple Seedlings. Plants 2019, 8, 580. [CrossRef]

65. Jin, X.; Liu, T.; Xu, J.; Gao, Z.; Hu, X. Exogenous GABA enhances muskmelon tolerance to salinity-alkalinity stress by regulating redox balance and chlorophyll biosynthesis. BMC Plant Biol. 2019, 19, 48. [CrossRef] [PubMed]

66. Müller, M.; Munné-Bosch, S. Rapid and sensitive hormonal profiling of complex plant samples by liquid chromatography coupled to electrospray ionization tandem mass spectrometry. Plant Methods 2011, 7, 37. [CrossRef]

67. Xu, H.; Zou, Q.; Yang, G.; Jiang, S.; Fang, H.; Wang, Y.; Zhang, J.; Zhang, Z.; Wang, N.; Chen, X. MdMYB6 regulates anthocyanin formation in apple both through direct inhibition of the biosynthesis pathway and through substrate removal. Hortic. Res. 2020, 7, 72. [CrossRef]

68. Livak, K.J.; Schmittgen, T.D. Analysis of relative gene expression data using real-time quantitative PCR and the $2^{-\Delta \Delta C T}$ Method. Methods 2001, 25, 402-408. [CrossRef] 